\title{
Blood Coagulation and Living Tissue Sterilization by Floating-Electrode Dielectric Barrier Discharge in Air
}

\author{
Gregory Fridman • Marie Peddinghaus • \\ Manjula Balasubramanian · Halim Ayan • \\ Alexander Fridman · Alexander Gutsol · Ari Brooks • \\ Gary Friedman
}

Published online: 5 November 2006

(C) Springer Science+Business Media, LLC 2006

\section{Erratum to: Plasma Chem Plasma Process DOI 10.1007/s11090-006-9024-4}

In the html of the original publication of this article on www.springerlink.com, the byline and author affiliations appear incorrectly.

The correct byline and affiliations are noted below:

Gregory Fridman $(\square)$

School of Biomedical Engineering,

Science, and Health Systems,

Drexel University,

The online version of the original article can be found at http://dx.doi.org/10.1007/s11090-006-9024-4

G. Fridman (ه)

School of Biomedical Engineering, Science, and Health Systems, Drexel University, 3141

Chestnut Street, Philadelphia, PA 19104, USA

e-mail: greg.fridman@drexel.edu

M. Peddinghaus $\cdot$ M. Balasubramanian

Pathology and Laboratory Medicine Department, College of Medicine, Drexel University,

245 N. 15th Street MS \#413, Philadelphia, PA 19102, USA

H. Ayan · A. Fridman · A. Gutsol

Department of Mechanical Engineering and Mechanics, College of Engineering, Drexel University, 3141 Chestnut Street, Philadelphia, PA 19104, USA

A. Brooks

Department of Surgery, College of Medicine, Drexel University, 245 N. 15th Street MS \#413, Philadelphia, PA 19102, USA

G. Friedman

Department of Electrical and Computer Engineering, College of Engineering, College of Engineering, Drexel University, 3141 Chestnut Street, Philadelphia, PA 19104, USA 
3141 Chestnut Street,

Philadelphia, PA 19104,

USA

e-mail: greg.fridman@drexel.edu

Marie Peddinghaus - Manjula Balasubramanian

Pathology and Laboratory Medicine Department,

College of Medicine,

Drexel University,

245 N. 15th Street MS \#413,

Philadelphia, PA 19102,

USA

Halim Ayan · Alexander Fridman · Alexander Gutsol

Department of Mechanical Engineering and Mechanics,

College of Engineering,

Drexel University,

3141 Chestnut Street,

Philadelphia, PA 19104,

USA

Ari Brooks

Department of Surgery,

College of Medicine,

Drexel University,

245 N. 15th Street MS \#413,

Philadelphia, PA 19102,

USA

Gary Friedman

Department of Electrical and Computer Engineering,

College of Engineering,

Drexel University,

3141 Chestnut Street,

Philadelphia, PA 19104,

USA 